\title{
ALÉM DO CÓDEX
}

\section{Ana Beatriz Barroso*}

\begin{abstract}
RESUMO: $O$ artigo explora o transbordamento da escrita e da leitura para fora das páginas. 0 texto, enquanto trama de sentidos e nexos, extrapola a dobra, marco fundamental na história do livro. Quando este deixa de ser rolo e passa a ser códex, quando este deixa de ser códex e passa a ser fluxo, quando essas passagens são percebidas mais como sobreposições e convivências de códigos distintos do que como exclusões e viradas radicais, sentimos a sutil flexibilidade dos conceitos fundamentais da cultura. A meta, então, é abordar algumas dessas convivências, observadas principalmente no diálogo entre as artes visuais e este precioso objeto de cultura, o livro. Para tanto, investigaremos algumas experiências artísticas contemporâneas que transitam pela relação do texto escrito com a imagem, bem como pelos escritos e livros de artista. Veremos, então, algumas possibilidades de abertura para o livro-códice na atualidade, quando experimentamos um contato ímpar com a presença massiva dos meios digitais de comunicação. Tal contato demanda uma compreensão renovada do próprio conceito de comunicação.
\end{abstract}

PALAVRAS-CHAVE: Livro. Hipertexto. Interatividade. Significação. Tessitura.

Como em um sonho, imagens de texto escrito fora das páginas manuscritas ou impressas de um livro bem feito, em forma de códice ou códex, nos vêm à mente. Começaremos por elas, descrevendo-as. Depois, perpassaremos algumas formas de poesia que já há muito se desgrudaram da página e ganharam os espaços tridimensionais. Saltaremos para as relações do artista com os livros, trazendo à tona algumas distinções e singularidades. Finalmente, chegaremos a uma encruzilhada entre dois caminhos inusitados que se abrem para além do códex quando a realidade cibernética se faz cotidiana e o hipertexto, em velocidade inconstante, exige de nós uma compreensão renovada do processo de leitura e do escrever. Uma compreensão que vá além do códex.

A poesia de tradição oral, que não se prende às regras da escrita e observa rigorosamente outros conjuntos normativos, como a metrificação rimada e ritmada do repente pernambucano, será estudada em outra ocasião. Isso porque nos interessa sobremaneira, neste momento, pensar tão somente a palavra grafada e o problema do espaço tempo experimentado em circuitos controlados pelas leis da linguagem matemática, algorítmica, o chamado espaço tempo cibernético

\footnotetext{
*Universidade de Brasília. abeatrizb@gmail.com
} 
(VENTURELLI, 2008) em relação ao espaço tempo experimentado fora desses circuitos. Ainda que a maioria de nós nem sequer as percebam, essas leis estão presentes na orquestração dos dados que ordenamos e lançamos por meio de nossos computadores domésticos na rede - internet. Em função desse interesse, eminentemente relacional, lançamos mão da metodologia transdisciplinar, a qual nos permite caminhar entre distintos campos do conhecimento, atravessando-os em busca daquilo que procuramos (NICOLESCU, 2005). Os campos que aqui percorremos compõem-se de fragmentos teóricos de fundamentação essencialmente semiótica, linguística e comunicacional.

Em diferentes graus, mais ou menos cônscios de que por trás das interfaces gráficas e iconológicas há uma língua numérica em operação, falamos com essas máquinas - os computadores - e falamo-nos através delas. Por essa razão, parece-nos pertinente lembrar que dentro delas há essa língua que um dia já se sonhou (e até hoje se quer) universal, capaz de resguardar e reproduzir simulações do próprio universo: a língua dos números. Como nós, leigos ou semianalfabetos nessa língua, não matemáticos, não programadores, mas simples usuários, simples falantes, podemos começar a ler e escrever nessa língua (ou com a lógica própria e específica dessa língua) e assim criar sentidos que só sejam possíveis nessa mesma língua?

Antes que nos encaminhem para um curso de computação, onde poderíamos aprender a lidar com a linguagem de programação, como muitos, outrora leigos, vêm fazendo, adianto que isso não resolveria o problema explicitado acima. A questão permaneceria latente, porque as transições históricas e culturais são efetivamente lentas, não se resolvem de modo prático, por meio de cursos, nem por iniciativas individuais, pontuais, ligadas a pequenos grupos. Ainda que possam se iniciar assim, em âmbito restrito, para que se concretizem, devem ser assimiladas por grande parte de seres humanos, em seus microuniversos ambulantes de valores, de latências, de aptidões múltiplas e de urgências variadas.

Esse argumento minimiza, de certo modo, um entendimento bastante 
disseminado, principalmente quando a computação chegou aos lares e se colocou ao alcance das mãos de muitos, em meados dos anos 1990, de que era (e é, por conseguinte) fundamental ensinar massivamente a linguagem de programação e a língua dos algoritmos a fim de emancipar o indivíduo das forças dominantes as grandes empresas do ramo, que nos fornecem os programas sem os quais simplesmente não conseguiríamos fazer quase nada com um computador. Ora, apesar de teoricamente sedutor, esse entendimento emancipatório parece utópico no momento atual (e não sabemos quanto tempo dura o presente) para a imensa maioria de nós, que foi meio que se alfabetizando em "computês" como pôde, intuitivamente, recorrendo às linguagens e recursos de linguagem que nos são familiares - a escrita, a iconologia, as metáforas. Bem ou mal, com esses recursos, conseguimos desfrutar da comunicação em rede, realizarmo-nos como falantes nessa teia e aí iniciarmo-nos como leitores e escritores de inúmeros meios de comunicação congregados em um só dispositivo.

Podemos, sim, dizer que somos leitores e escritores multimidiáticos ainda que não mergulhemos no oceano cibernético, nem nele naveguemos soltos em barcos à vela. Somos simples viajantes em cruzeiros e embarcações capitaneados por marinheiros poliglotas, conhecedores de muitos mares (e interesses) - os programadores, os hackers e as grandes empresas, que nos fornecem tecnologias de navegação mais ou menos seguras, ainda que menos aventureiras e desbravadoras. Por meio dessas ferramentas de criação multimídia e hipertextual - blogger, tumblr, flickers, facebooks, e-mail, buscadores - vamos trocando ideias e compartilhando vivências, vamos nos falando, nos vendo, nos lendo e nos escrevendo.

Uma vez dito isto, podemos tomar mais consciência de que há uma trama de códigos em ação aí (na teia e fora dela) e aprimorar nossa capacidade de compreensão do potencial comunicativo desse sistema multicodificado, tanto para aí inserir nosso micro sistema de codificação (nossos entendimentos e mensagens), quanto para descodificar os microssistemas de codificação dos outros. Codificar e descodificar de modo criativo, inusual, crítico e singular implica se abrir para a ideia de autoria, indo além do uso corriqueiro da linguagem, seja 
ela qual for. Ao trabalhar com a noção de que é possível realizarmo-nos como autores, isto é, criadores de sentidos singulares, no ciberespaço, estamos nos aventurando a pensar na autoria de livros dessemelhantes ao códex, isso porque, ao que nos parece, o meio de comunicação até agora mais próximo do meio ciberespacial é o livro, posto que em ambos prevalece a linguagem escrita entremeada de imagens, em ambos mobilizamos nossas habilidades de leitura e de escrita, em ambos elaboramos e articulamos conhecimento, ainda que em diferentes medidas e de diferentes modos.

O livro virtual, chamemos assim esse livro desfolhado feito de dígitos, transcende a fisicidade do livro-códex, em seu aspecto estrutural e material, mas preserva (ou pode preservar) sua densidade comunicacional. Esta se observa na articulação entre as instâncias comunicadoras, classicamente definidas como emissor, receptor, mensagem, canal, código e referente (JACKOBSON, 2004). Ora, no livro que está além do códex, essa articulação se altera, pois a relação que se estabelece entre as instâncias se transforma, mas, ao mesmo tempo, a estrutura fundamental do jogo linguístico próprio do livro continua existindo. Como essa transformação e esta permanência se dão é o que estudaremos a seguir.

\section{Textos soltos pelas ruas}

Um grafite eletrônico usa a fachada de um prédio como suporte para palavras escritas em grandes dimensões por alguém munido de uma tecnologia a laser. Trata-se de uma espécie de caneta-vara conectada (sem fio) a um projetor capaz de ampliar imensamente o grafismo feito no ar. A pessoa escreve, assim, no vazio e o que ela escreve aparece lá longe, agigantado, em luz verde na parede lateral do prédio ${ }^{1}$. A ação acontece à noite. O efeito é mágico. Quem passa, de carro ou à pé, vê essas palavras soltas substituindo-se sem conexão aparente. Prevalece a sensação de experimento com um novo brinquedo. $O$ aspecto lúdico contagia a cena, não importa o que será escrito, importa escrever daquele jeito, ali. Os grafismos são desenhados livremente. Transita-se por palavras, mas também

1 Cf.disponível em $<$ http://www.youtube.com/watch?feature=player embedded\&v=EFWcAkxzkv4>. Acesso em maio de 2012. 
algumas figuras surgem eventualmente. Depois de algum tempo, os artistas grafiteiros vão embora, simplesmente.

Semelhante a essa experiência de escritura/leitura de palavras em um contexto urbano, onde o suporte do texto é a parede externa de uma edificação, temos a proposta intitulada CIURBI, ciberintervenção urbana interativa ${ }^{2}$. Nela, um mecanismo de inteligência artificial é usado para captar palavras enviadas via Twitter por pessoas interessadas em participar da experiência. As pessoas devem postar em seus Twitters, em um dia e horário determinados, mas de um local qualquer, de onde estiverem, de suas casas, automóveis, ambientes de trabalhos, dos quatro cantos do mundo, uma palavra ou frase. É importante que essas palavras ou frases terminem com @ciurbi. Isso feito, a mensagem é projetada no local da ciberintervenção. Para que isso aconteça, um mecanismo de inteligência artificial, desenvolvido pelos artistas computacionais responsáveis pela proposta, entra em ação. O efeito é belo e instigante.

Anteriores a essas experiências, mas igualmente fascinantes, são as inscrições manualmente grafadas nos muros das cidades, nas portas de banheiros, sobre as carteiras escolares. Ali deixados como expressão anônima, sujeitos à intervenção de outras pessoas, esses grafismos compõem um texto mal tecido, esfarrapado, delirante e urgente. Nessa soltura, nessa fluidez, onde o simbólico convive com o icônico e onde a plasticidade se encontra no aleatório dos suportes-canais-meios (pedra, cal, madeira descascada) e dos materiais usados na escritura (caneta, tinta, faca que fere e risca), encontra-se a beleza expressiva dessas páginas soltas. Essa beleza nos alerta para a possibilidade de lermos o mundo ou de estarmos no mundo como leitores atentos, decifrando signos onde quer que eles se encontrem, onde quer que nos encontremos. Tal estado de atenção nos permite criar significação e dar sentido à existência. Restaura-se, assim, a noção de que a pessoa é autora do próprio viver e que, anônima e discretamente, inventa-se e inscreve-se no mundo. As imagens, uma popular, outra erudita, da vida como um livro aberto e do universo como uma imensa biblioteca (Jorge Luis Borges), são ilustradas por essas experiências de inscrições aleatórias

2 Cf. disponível em <http://ciurbi.wordpress.com/>. Acesso em maio de 2012. 
encontradas em abundância nas cidades.

Do mesmo modo, mas agora em outros suportes, vemos textos soltos perambulando pelas ruas estampados em camisetas e tatuados nos corpos. Não incluímos aqui os letreiros publicitários, as fachadas das lojas nem os outdoors, porque entendemos que esses textos não são tão soltos quanto aparentam ser; estão presos a ideais muito precisos e cumprem finalidades opostas às que queremos valorizar neste estudo. Aqui, visamos valorizar o potencial de criaçãoautoria do sujeito (ou da pessoa) na atualidade. Potencial este, que tem se manifestado de múltiplas formas, na arte institucional, na arte bruta, na arte urbana, na arte computacional.

Esta pluralidade que a arte experimenta no presente, esse desprendimento que teoricamente ela conquistou e vem conquistando, há de ser devidamente assimilado, percebido. Ora, a arte, hoje, conhece uma liberdade ímpar. Ela pode ser o que quiser, tanto em termos conceituais, quanto em termos de técnicas. Há inúmeros meios, tecnologias, arcabouços teóricos, suportes, materiais e instrumentos sendo empregados pelos artistas contemporâneos. Além disso, há um leque bem amplo de meios de difusão e de modos de fruição participação e interação com a arte. Reconhecer essa liberdade implica em querer conhecer sua potência libertária. Veremos um pouco como ela se manifesta no caso específico da relação do artista com o objeto que aqui estamos explorando: o livro.

\section{Livros e artistas}

No início e ao longo do século XX, ocorre um estreitamento curioso da relação do artista com a escrita. Cartas, diários, artigos em revistas e jornais, manifestos e livros passam a ser o espaço de comunicação usado por pintores, cineastas, músicos, artistas em geral, para difundir e legitimar suas visões de arte; visões essas, já libertas de uma série de estigmas e valores, ora acadêmicos, ora religiosos, ora estritamente comerciais. Essas visões, expostas e compartilhadas naqueles meios de comunicação onde prevalece a escrita, intervêm na esfera cultural. É nessa esfera que a arte vai, de modo mais nítido a partir do século 
passado, habitar; é com a cultura, no plano da cultura (e da contracultura), que a arte firma seu compromisso e se posiciona em relação a uma série de questões, saindo de sua suposta esfera de pureza, a qual talvez, a rigor, nunca tenha existido. Isso significa que aquele movimento, iniciado com as vanguardas europeias, de ocupação da esfera midiática, onde a cultura-contracultura global se tece, reverbera na arte contemporânea, lançando-a, para além da expressão, no campo do conhecimento, da experiência, da partilha, do acontecimento político e da convivência, ora espetacular, ora ritualística, ora simplesmente pessoal e investigativa, íntima, literária e poética.

Neste contexto (ou nesta visão), o livro, como objeto de cultura por excelência, como lugar de elaboração e compartilhamento de visões, tradições e saberes, como concreção da prática social/individual de escrita e leitura de texto, ganha relevo. Na sua relação com a arte, vemos algumas categorias se distinguirem. Pensamos em um primeiro momento no livro escrito por artistas, onde esses expõem suas teorias sobre suas artes ou as questões de seu tempo. Temos aqui, só para ficar nos mais conhecidos, as cartas de Van Gogh a Théo, os diários de Gauguin, o Libelo contra a Arte Moderna, de Dalí, a Teoria da Arte Moderna, de Paul Klee, o belíssimo Do espiritual na Arte, de Kandinsky, O Sentido do Filme, de Eiseinstein, a Introdução a uma Verdadeira História do Cinema, de Godard, Esculpir o Tempo, de Tarkovski.

Paremos por aqui, pois não é nossa intenção listar exaustivamente, mas apenas indicar, a título de exemplo, que a literatura sobre pintura e sobre cinema feita pelos próprios pintores e cineastas, nesses casos, é farta. E não só sobre a própria arte. Os artistas, de um modo geral, tornam-se profícuos escritores. "Escrever para mim, Clarice, é um prazer tão grande que nem sei explicar, e menos penoso do que esculpir. Mas nunca chego a dizer exatamente o que eu queria” (MARTINS apud LISPECTOR, 2007, p. 189).

Outra categoria ou modo como a relação do artista com o livro se dá configura-se no chamado livro de arte. Nas publicações desse tipo, o artista e sua arte são o assunto ou a temática em torno da qual o texto se tece. São livros sobre arte, 
sobre Dalí, sobre Picasso, sobre Beatriz Milhazes, sobre Henri Matisse, sobre o Expressionismo, sobre a Pop Art, sobre Diego Rivera etc. Escritos por curadores, historiadores, teóricos ou críticos de arte, esses livros costumam ser belamente editados a fim de garantir o rigor cromático e a reprodução fiel das obras comentadas. Sem dúvida, constituem-se em material importante para estudo e pesquisa, fonte de conhecimento fundamental, tanto para os que têm a oportunidade de viajar e conhecer pessoalmente algumas obras de arte, quanto para os que não têm. Isso, porque o trabalho editorial envolvido nessas publicações nos dá acesso ao olhar do especialista, que tende a contextualizar a obra e a nos falar de coisas que não estão ali, explicitamente visíveis na obra, mas que fazem parte do tempo dela, da cultura que a berça, das coisas invisíveis que a geram e cercam.

Uma categoria próxima a esta é a do livro teórico e de história da arte; de entrevistas com artistas; de biografias e de estudos aprofundados sobre um ou outro artista, como o do poeta Octávio Paz sobre Marcel Duchamp - Marcel Duchamp ou o Castelo da Pureza. Esses livros assemelham-se àqueles supramencionados. Deles diferem, no entanto, por apresentarem conteúdo mais textual que imagético. O que está em foco, neles, é a reflexão propriamente teórica sobre o assunto tratado.

Já os chamados livros de artista são obras de aspecto variado, que adquirem feições múltiplas, de acordo com a criatividade do artista. Geralmente, são oriundos de cadernos de esboço e de estudo, de diários manuscritos (El Diario de Frida Khalo), de experimentos com artes gráficas, de pesquisas que tenham por objeto a relação palavra-imagem. Nesse caso, se insere, por exemplo, a obra da poeta visual Leonora de Barros, na qual se cria uma tensão ímpar na relação símbolo-ícone ${ }^{3}$.

Importa, aqui, perceber que, por mais variadas que essas experiências sejam, o livro de artista se caracteriza por ser um espaço onde a forma, ou o lugar

3 Vide entrevista da artista ao programa Entrelinhas, disponível em $<$ http://www.youtube.com/watch?v=irBip6ZWu7M\&feature=youtu.be $>$. Acesso em maio de 2012. 
relacional, típico do códex, é discutido e utilizado de maneira inventiva. As páginas, o formato, a textura das folhas, a organização gráfica, a opção pelo manuscrito ou pelo tipológico, não são escolhidos com o propósito exclusivo de servir adequadamente como suporte/canal/meio para o texto, para o conteúdo, digamos assim, mas, indo além dessa função fática (focada no canal ou meio de comunicação), tudo aquilo que tradicionalmente é da ordem do significante tende aqui, no livro de artista, a ser significado.

O que se vê em jogo no livro de artista, em alguns momentos, se assemelha ao que se vê nos livros de poesia concreta e neoconcreta. Nessas construções, as palavras, signos essencialmente simbólicos, ganham concretude, ganham iconicidade, querem se parecer visual e graficamente ao que, simbolicamente, representam. A dimensão plástica do livro e da página é valorizada. Os exemplos vão desde Apollinaire até os irmãos Haroldo e Augusto de Campos, passando por Décio Pignatari, Reynaldo Jardim e o Suplemento Literário do Jornal do Brasil, bem como pelas experiências extremas, neoconcretas, de Ferreira Gullar - livropoema, teoria do não-objeto, poemas espaciais e poema enterrado. Cabe lembrar que este último "foi o precursor de uma série de obras que seriam realizadas por Hélio [Oiticica] e Lygia [Clark]" (GULLAR, 2007, p. 61).

Somam-se a esses, alguns expoentes da cultura brasileira contemporânea, como Arnaldo Antunes e o saudoso Paulo Leminski, que nos mostram como a tensão signans/signatum, significante/significado, expressão/conceito, é fonte de criações estéticas profícuas e abundantes.

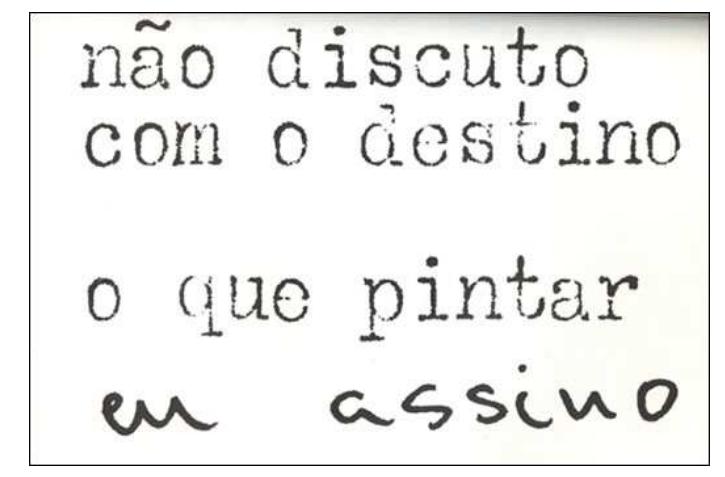

Fig. 1. Sem título. Paulo Leminski, 1980. 
Quando, neste amálgama, a balança pesa mais para o lado da expressão, deparamo-nos com o livro objeto. Nele, suporte, forma, cheiro e movimento são explorados. Pouco importa o que se diz neste livro, sua dimensão objetual se sobrepõe ao conteúdo. O códex aqui ganha novas feições. Temos, por exemplo, um livro que pulsa e respira, como se tivesse um coração em seu interior. Trata-se da obra Livro corpo (2009), do artista Rodrigo Paglieri (Chile, 1969). Temos também a profusão de livros-escultura da artista britânica Su Blackwell, onde formas saem das páginas e assumem tridimensionalidade (Fig. 2). O livro, a página impressa e a textura das letras tornam-se aqui matéria-prima, suporte e corpo de uma imagem visual que prescinde da organização encadeada das palavras, típica da construção textual escrita. O conjunto, inegavelmente associado ao livro e dele derivado, traduz diretamente, em função da forma expressiva criada pela artista, o conceito que deseja comunicar.

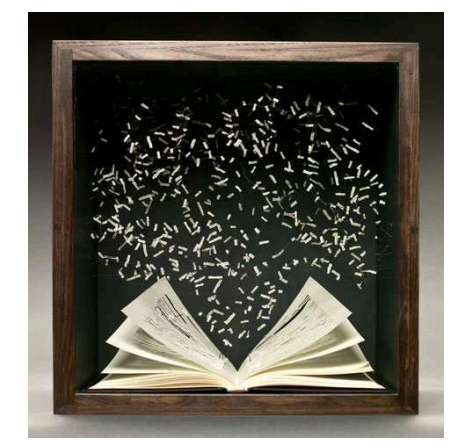

Fig. 2. The Book of the Lost. Su Blackwell. 2011

\section{Além do livro}

Finalmente, chegamos a formas de escrita e de leitura que só são possíveis em outro meio que não o impresso. Trata-se do meio cibernético, onde o texto escrito ganha tal fluidez e plasticidade que, por mais que ainda reconheçamos nele elementos que nos são familiares e que nos permitem identificá-los, ora como jornais, ora como revistas, ora até como livros (sendo essa última identificação a 
mais problemática), somos forçados a admitir que tais elementos estruturais tornam-se mais e mais dispersos e irreconhecíveis à medida que o tempo passa. Por essa razão, nos lançamos na pesquisa da transposição dos limites do livro, tal como o conhecemos classicamente.

Roger Chartier (2002), pesquisador da história do livro, vem usando a expressão texto eletrônico para falar deste além-livro que experimentamos em nossas práticas diárias de escrita e leitura na grande rede mundial de computadores (world wide web). Ele nos chama a atenção para uma série de fatores importantes a serem considerados quando se tenta compreender essa experiência à luz da história do livro. Dentre esses fatores, se destacam: o excesso de informação, já conhecido na cultura livresca e literária de tradição européia desde meados do século XIX; a convivência de formas distintas de texto escrito, o manuscrito e o impresso, este e o digital; e finalmente, o que mais nos interessa, a revolução da dobra, que de fato deu origem ao códex, alterando uma série de práticas de escrita e de leitura associadas ao livro de rolo. Correspondente a esta revolução, o pesquisador nos aponta outra: o desaparecimento da dobra e a abertura rizomática do hipertexto multimídia, que é o texto eletrônico presente na internet.

Diante dessas constatações e das propostas artísticas e poéticas descritas anteriormente, podemos imaginar duas aberturas possíveis para o códex. Uma é de cunho subjetivo e nos obriga a trabalhar pela transformação de nossas concepções corriqueiras de escrita e de leitura, ampliando esses conceitos. Nesse sentido, cabe retomar algo que não é uma novidade, mas que se esquece com frequência. Trata-se de lembrar que o processo de leitura não se restringe à descodificação do texto escrito, mas se aplica a um processo amplo de significação, isto é, de associação de uma forma (significante) a um conceito (significado) por alguém ou algo em um contexto (interpretante). Por essa via, podemos chegar à conclusão de que o mundo é um livro entreaberto e que estar vivo é escrever e ler neste livro obscuro e incerto. Cultura e natureza nos instruiriam no processo escorregadio desta alfabetização arriscada, de graves e inevitáveis consequências existenciais. Neste processo, conhecer e inventar se confundem. 
Essa abertura de cunho subjetivo, embora pouco original e essencialmente metafórica, é preciosa. Ela nos remete a culturas ágrafas, onde as pessoas desenvolviam (e desenvolvem) outros sentidos e outras formas de associação de ideias - leem as gotas de chuva, a cor do céu, a expressão de um olhar. A literatura de Mia Couto (2003) nos dá belos exemplos dessas formas de leitura próprias de um universo comunicacional marcado pela força da oralidade. Apurar os ouvidos e os outros sentidos, que foram sendo pouco a pouco intimidados pela predominância do sentido visual, restauraria uma parte não desprezível de nossa relação original com o mundo circundante. Não se trata de tentar retroceder ou reverter um processo de aculturação cuja ordem de complexidade ultrapassa esse único aspecto. Trata-se apenas de apontar para um horizonte onde o humano possa ser vislumbrado de modo mais integral em seu próprio aparato sensório-intelectivo, em seu corpo e no mundo técnico e natural do qual é parte integrante.

A outra abertura imaginada é de cunho objetivo. Ela dá prosseguimento à anterior, a subjetiva. Se esta nos abre para possibilidades multissensoriais de conhecer e de inventar sentidos para a existência - pois esta não raro nos soa sem sentido e absurda - a abertura objetiva dos limites do códex implica na exploração de múltiplas linguagens e meios, inclusive naqueles construídos a partir do silêncio. No filme Pina, de Wim Wenders (110 min. França-Alemanha, 2011), fica claro como em Pina Bausch a dança é trabalhada como linguagem, em termos de vocabulário, começando onde está o silêncio, onde as palavras não chegam. Nesse sentido, é que pensamos o além-livro como um livro não só (objetualmente) multimídia - como o são os espetáculos de dança, de cinema, de música, de teatro, quando os sentidos se tecem e a significação acontece por meio de um processo de descodificação que transcende o textual -, mas, sobretudo, como um livro que procura ir além do discurso.

Ora, se a comunicação é classicamente entendida dentro dos limites do discurso e das ordens (sociais, políticas, culturais, ideológicas) que o regem e que, por meio dele, regem as pessoas, muitas vezes subtraindo delas sua beleza 
essencial, indomável e única, não aculturada (FOUCAULT, 2009), interessa-nos colocar os pés para fora desse limite discursivo, desse vai-e-vem entre texto e contexto (BARTHES, 1994), dessa correria cansativa em busca de nexos e sentidos para o que não faz nexo nem sentido, mas que, ainda assim, é, existe, tem vida. Para tanto, é preciso lembrar que a comunicação não são se restringe a este limite discursivo. Embora ele a defina e lhe dê forma, ela transborda o discurso, ela trai a intenção, ela estranha a razão, ela nos leva a pensar em um universo racional mais amplo, menos imediatamente utilitário e prático.

Além do sentido discursivo, materializado sobremaneira no artefato midiático "livro", a comunicação resguarda o sentido primevo de conexão, algo que acontece misteriosamente, algo que se dá de repente, de modo inesperado, algo que não é correria, mas lentidão, algo que não é falatório, mas quietude, grito, pausa, sentimento ou sensação. Este sentido (de comunicação como conexão e sintonia) encontra por sua vez possibilidades ímpares de se concretizar no meio múltiplo, gigantesco e fluido, que é a rede mundial de computadores e que são ao mesmo tempo as inúmeras linguagens da arte, dentro e fora desta rede, que, ao criarem perturbações significativas na ordem discursiva habitual (e, por conseguinte, naquilo que engendra essa ordem) se realizam como um além do códex. Cabe a nós, portanto, tão somente, conviver neste além.

\section{BEYOND THE CODEX}

ABSTRACT: The article explores the overflow of writing and reading out of the pages. The text as a network of meaning and connections goes beyond the fold, boundary in the history of the book. When the book is no longer a roll and becomes a codex, when the codex becomes a flow, when these passages are perceived more as overlays and cohabitation of different codes than as exclusions or radical ruptures, we can feel the subtle flexibility of the fundamental concepts of culture. The purpose then is to address some of these shared experiences, observed mainly in the dialogue between the visual arts and this precious object of culture, the book. To do so, we will investigate some contemporary artistic proposals that pass by the relation of the written text with the image, and also by the artist's writings and books. We'll then open some possibilities for the book-codex today, when we all experience a strong contact with the massive presence of the digital communication, which demands a renewed understanding of the concept of communication itself.

KEY WORDS: Book. Hypertext. Interactivity. Significance. Weaving. 


\section{Referências}

BARTHES, Roland. Fragmentos de um Discurso Amoroso. Rio de Janeiro: Francisco Alves, 1994.

BORGES, Jorge Luis. O Livro de Areia. São Paulo: Companhia das Letras, 2009.

CHARTIER, Roger. Os Desafios da Escrita. São Paulo: Editora UNESP, 2002.

COUTO, Mia. Um Rio Chamado Tempo, uma Casa Chamada Terra. São Paulo: Companhia das Letras, 2003.

DALÍ, Salvador. Libelo Contra a Arte Moderna. Porto Alegre: L\&PM Editores, 2008.

EISENSTEIN, Sergei. O Sentido do Filme. Rio de Janeiro: Jorge Zahar, 2002.

FOUCAULT, Michel. A Ordem do Discurso: aula inaugural no Collège de France, pronunciada em 2 de dezembro de 1970. São Paulo: Loyola, 2009.

GAUGUIN, Paul. Noa Noa - viagem ao Tahiti. Rio de Janeiro: Philobiblion, 1993.

GODARD, Jean-Luc. Introdução a uma Verdadeira História do Cinema. São Paulo: Martins Fontes, 1989.

GULLAR, Ferreira. Experiência Neoconcreta: momento-limite da arte. São Paulo: Cosac Naif, 2007.

JAKOBSON, Roman. Lingüística e Comunicação. São Paulo: Cultrix, 2010.

KAHLO, Frida. El Diario de Frida Kahlo. México: La Vaca Independiente, 2005.

KANDINSKY, Wassily. Do Espiritual na Arte. São Paulo: Martins Fontes, 1990.

KLEE, Paul. Théorie de l'art moderne. Paris: Denoël, 1985.

LEMINSKI, Paulo. Não fosse isso e era menos, não fosse tanto e era quase (de 63 pra cá). Curitiba: Editora Zap, 1980.

MARTINS, Maria. A Juventude sempre tem Razão. In : LISPECTOR, Clarice. Entrevistas/Clarice Lispector. Rio de Janeiro: Rocco, 2007.

NICOLESCU, Basarab. O Manifesto da Transdisciplinaridade. São Paulo: Triom, 2005.

PAZ, Octávio. Marcel Duchamp ou o Castelo da Pureza. São Paulo: Perspectiva, 2004. 
TARKOVSKI, Andrei. Esculpir o Tempo. São Paulo: Martins Fontes, 1990.

VENTURELLI, Suzete; MACIEL, Mário. Imagem Interativa. Brasília: Edunb, 2008.

WENDERS, Wim. Pina. 110 min. Alemanha-França: 2011.

Texto recebido em 04/06/2012 